\title{
Long non-coding RNA RPSAP52 upregulates Timp3 by serving as the endogenous sponge of microRNA-365 in diabetic retinopathy
}

\author{
TONGTONG NIU, YAN AN, TINGTING LV and DONGNING LIU \\ Department of Ophthalmology, The Fourth People's Hospital of Shenyang, \\ Shenyang, Liaoning 110031, P.R. China
}

Received October 1, 2019; Accepted May 20, 2020

DOI: $10.3892 / \mathrm{etm} .2020 .9376$

\begin{abstract}
Diabetic retinopathy (DR) is a serious complication of diabetes and the most common metabolic disorder. Recently, long non-coding (lnc)RNAs have been identified as critical regulators of DR. Ribosomal protein SA pseudogene 52 (RPSAP52) is an oncogenic lncRNA expressed in pituitary tumors. The present study aimed to investigate the functions of RPSAP52 in DR. RPSAP52 levels in the plasma of diabetic patients with or without DR complication was detected. Luciferase reporter assays, RT-qPCR and western blotting were performed to detect the interaction between RPSAP52 and micro RNA (miR)-365. Moreover, expression vectors of RPSAP52 and Timp3, as well as miR-365 mimics were transfected into ARPE-19 cells exposed to high glucose and the apoptotic cells were detected. The results showed that RPSAP52 was downregulated in patients with DR compared with patients with diabetes without obvious complications. RPSAP52 directly interacted with miR-365, while overexpression of RPSAP52 and miR-365 did not affect the expression of one another. In addition, overexpression of RPSAP52 upregulated TIMP metallopeptidase inhibitor 3 (Timp3) in retinal pigment epithelial (RPE) cells. High glucose treatment led to downregulated RPSAP52 and Timp3, but upregulated miR-365 in RPE cells. Moreover, cell apoptosis analysis identified that overexpression of RPSAP52 and Timp3 led to a decreased apoptotic rate of RPE cells under high glucose treatment. Therefore, it was speculated that RPSAP52 may upregulate Timp3 by serving as the endogenous sponge of miR-365 in DR to suppress RPE cell apoptosis.
\end{abstract}

Correspondence to: Dr Dongning Liu, Department of Ophthalmology, The Fourth People's Hospital of Shenyang, 20 Huang Henan Street, Huanggu, Shenyang, Liaoning 110031, P.R. China

E-mail: rh0654@163.com

Key words: ribosomal protein SA pseudogene 52, diabetic retinopathy, microRNA-365, TIMP metallopeptidase inhibitor 3, apoptosis

\section{Introduction}

Diabetes is the most commonly diagnosed metabolic disorder in clinical practice; it is estimated that $>280$ million people have diabetes worldwide $(1,2)$. The long-term development and progression of diabetes can affect multiple organs, leading to the occurrence of diabetic complications (3). Moreover, diabetic retinopathy (DR) is a common complication of diabetes and is a major cause of vision-loss globally $(4,5)$. DR is caused by high-glucose mediated damage of the blood vessels in the light-sensitive tissue of retina $(4,5)$. However, despite the development of various therapeutic approaches, such as intravitreal injections of steroids, anti-vascular endothelial growth factor agents and laser photocoagulation, blindness will inevitably occur in $\sim 10 \%$ of patients with DR (6). Therefore, investigation into novel therapeutic approaches remains of great importance.

Along with hyperglycemic conditions, the progression of DR also involves in multiple genetic factors $(7,8)$. For example, the polymorphism of Aldose Reductase gen has been found to be a risk factor of DR with type-2 diabetes (9). The genetic variant in miR-449b is significantly associated with Caucasian patients with type-1 diabetes (10). Thus, the identification and functional characterization of genetic factors involved in the molecular pathogenesis of DR may provide novel insights into the treatment of DR (11). TIMP metallopeptidase inhibitor 3 (Timp3) is a critical component in glucose homeostasis, and intravitreal injection of Timp3 has protective effects in a retinopathy mouse model $(12,13)$. Furthermore, microRNA (miRNA/miR)-365 can target Timp3 to promote the development of DR (14). In a previous study, preliminary bioinformatics analysis results revealed that miR-365 could also target ribosomal protein SA pseudogene 52 (RPSAP52), which is an oncogenic long non-coding (lnc)RNA in pituitary tumors (15). Therefore, the aim of the present study was to investigate the interactions between miR-365, RPSAP52 and Timp3 in DR.

\section{Patients and methods}

Research subjects. This study was approved by the Ethics Committee of The Fourth People's Hospital of Shenyang (Shenyang, China). Research subjects included 60 patients 
with DR (age, 47-68 years), 60 patients with diabetes (age, 47-68 years) and 60 healthy controls (age, 47-68 years). All these participants were enrolled at the aforementioned hospital between March 2017 and March 2019. All patients were diagnosed for the first time and no other clinical disorders were diagnosed. No therapies were performed within 3 months before admission. The basic information of the three groups of participants is presented in Table I. According to National Institute on Alcohol Abuse and Alcoholism, heavy alcohol drinking defined as average intake of $>7$ drinks per week for women and $>14$ drinks per week for men (16). No significant differences in basic information, except body mass index were identified among the three groups. All participants signed informed consent.

Plasma and retinal pigment epithelial (RPE) cells. Blood $(5 \mathrm{ml})$ was extracted under fasting conditions from all participants before the initiation of therapies. Blood samples were centrifuged at $1,200 \mathrm{x}$ g in EDTA tubes at $4^{\circ} \mathrm{C}$ for $10 \mathrm{~min}$ to prepare plasma samples. The human RPE cell line ARPE-19 (American Type Culture Collection; cat. no. CRL-2302) was used. Cells were cultivated under conditions of $37^{\circ} \mathrm{C}, 5 \% \mathrm{CO}_{2}$ with DMEM/F12 Medium (Thermo Fisher Scientific, Inc.) containing 10\% FBS (Sigma-Aldrich; Merck KGaA).

Cell transfections. Expression vectors of RPSAP52 (accession no. NR_026825.2) and Timp3 (accession no. NM_000362.5) were established using pcDNA3.1 vector (Sigma-Aldrich; Merck KGaA) between EcoRI and EcoRV cleavage sites as the backbone. Negative control (NC) miRNA (5'-GUGUGG UUCGGAAAUUCCACAG-3') and miR-365 mimic (5'-UAA UGCCCCUAAAAAUCCUUAU-3') were also purchased from Sigma-Aldrich (Merck KGaA). Cells were cultivated at $75-85 \%$ confluence and manually counted using a hemocytometer. Then, $10^{6}$ cells were transfected with $50 \mathrm{nM}$ miRNA or $10 \mathrm{nM}$ vector via transient transfections using Lipofectamine ${ }^{\circledR} 2000$ reagent (Invitrogen; Thermo Fisher Scientific, Inc.). In total, two control groups were included: i) Control (C), untransfected cells; and ii) NC, empty pcDNA3.1 or miRNA NC transfection. Transfections were performed at $37^{\circ} \mathrm{C}$ for $6 \mathrm{~h}$. Cells were collected at $24 \mathrm{~h}$ post-transfection to perform the following experiments.

Luciferase reporterassay. The potential binding site of miR-365 on RPSAP52 was predicted by IntaRNA 2.0 (http://rna.informatik.uni-freiburg.de/IntaRNA/Input.jsp). The RPSAP52 vector was constructed by inserting the full-length cDNA of RPSAP52 (accession no. NR_026825.2) into pmirGLO vector (Promega Corporation). RPSAP52 vector was co-transfected into $10^{6}$ cells with miRNA NC or miR-365 mimic via aforementioned methods. A dual-luciferase reporter gene assay system (Promega Corporation) was used to measure luciferase activity in cells collected at $24 \mathrm{~h}$ post-transfection. Renilla luciferase activity was used to normalize the relative luciferase activity.

$R N A$ preparations and reverse transcription-quantitative PCR (RT-qPCR). RNAiso Plus (Takara Biotechnology Co., Ltd.) was used to extract total RNA from both in vitro cultivated cells and in vivo plasma from patients. Cells were cultivated in DMEM/F12 medium containing 10, 20 and $30 \mathrm{mM}$ D-glucose (Shanghai Aladdin Bio-Chem Technology Co., Ltd.) at $37^{\circ} \mathrm{C}$ for $24 \mathrm{~h}$ before use. LookOut ${ }^{\circledR}$ DNA Erase (Sigma-Aldrich; Merck KGaA) was used to digest all RNA samples to remove genomic DNA. Total RNAs were reverse transcribed into cDNAs using the SSRT IV system (Thermo Fisher Scientific, Inc.) under the following conditions: $25^{\circ} \mathrm{C}$ for $10 \mathrm{~min}, 55^{\circ} \mathrm{C}$ for $30 \mathrm{~min}$ and $85^{\circ} \mathrm{C}$ for $10 \mathrm{~min}$. The qPCR reaction mixtures were prepared using SYBR Green PCR kit (Takara Biotechnology Co., Ltd.). GAPDH was used as endogenous control for the expression levels of RPSAP52 and Timp3. PureLink miRNA Isolation kit (Thermo Fisher Scientific, Inc.) was used to extract miRNAs from the samples. All-in-One ${ }^{\mathrm{TM}}$ miRNA RT-qPCR reagent kit (GeneCopoeia, Inc.) was used to measure the expression of miR-365 with U6 as endogenous control. Primer sequences were: RPSAP52 forward, 5'-GGACCTGGGAGA AGCTTCTG-3' and reverse, 5'-CCAGGAGTGAAGTGG CCAGC-3'; Timp3 forward, 5'-CCAGGACGCCTTCTG CAACT-3' and reverse, 5'-CATCTTGGTGAAGCCTCG GT-3'; GAPDH forward, 5'-CATCACTGCCACCCAGAA GACTG-3' and reverse, 5'-ATGCCAGTGAGCTTCCCG TTCAG-3'; and miR-365 forward, 5'-TAATGCCCCTAA AAATCCTT-3' and reverse, 5'-GCGAGCACAGAATTA ATACGAC-3'; U6 forward, 5'-GCTTCGGCAGCACATATA CTAAAAT-3' and reverse, 5'-CGCTTCACGAATTTGCGT GTCAT-3'. PCR conditions were as follows: Initial denaturation at $95^{\circ} \mathrm{C}$ for $10 \mathrm{~min} ; 40$ cycles at $95^{\circ} \mathrm{C}$ for $10 \mathrm{sec}$ and $56^{\circ} \mathrm{C}$ for $50 \mathrm{sec}$; final annealing at $72^{\circ} \mathrm{C}$ for $10 \mathrm{~min}$. The $2^{-\Delta \Delta C \mathrm{Cq}}$ method (17) was used to calculate the fold changes of gene expression levels across samples. All PCR reactions were repeated three times.

Western blot analysis. Transfected cells were harvested at $24 \mathrm{~h}$ post-transfection and were washed twice with PBS. Cells were mixed with RIPA solution (Beyotime Institute of Biotechnology) to prepare cell lysates. A bicinchoninic acid protein assay kit (Beyotime Institute of Biotechnology) was used to measure the protein concentration, followed by protein denaturation in boiling water at $100^{\circ} \mathrm{C}$ for $10 \mathrm{~min}$. Then, $25 \mu \mathrm{g}$ protein was separated by $12 \%$ SDS-PAGE and was transferred to PVDF membranes. After being blocked with $5 \%$ skim milk for $1 \mathrm{~h}$ at $4^{\circ} \mathrm{C}$, rabbit primary antibodies of Timp3 (1:500; cat. no. ab39185; Abcam) and GAPDH (1:1,000; cat. no. ab8425 Abcam) were incubated with the membranes at $4^{\circ} \mathrm{C}$ for $12 \mathrm{~h}$. Then, horseradish peroxidase-conjugated goat anti-rabbit (IgG) secondary antibody (1:1,000; cat. no. ab97051; Abcam) was further incubated with the membranes at $25^{\circ} \mathrm{C}$ for $2 \mathrm{~h}$. An ECL assay (EMD Millipore) was performed to produce signals, which were normalized using ImageJ v1.48 software (National Institutes of Health).

Flow cytometry to analyze cell apoptosis. Transfected cells were harvested at $24 \mathrm{~h}$ post-transfection and were seeded onto a 6 -well plate $\left(10^{5}\right.$ cells per well), followed by cell culturing in DMEM/F12 medium containing $30 \mathrm{mM} \mathrm{D}$-glucose under $5 \% \mathrm{CO}_{2}$ at $37^{\circ} \mathrm{C}$ for $48 \mathrm{~h}$. Cells cultured in DMEM/F12 medium without D-glucose under $5 \% \mathrm{CO}_{2}$ at $37^{\circ} \mathrm{C}$ (normal condition) were used as the control. Subsequently, cells were 
Table I. Basic information of the three groups of participants.

Diabetic retinopathy $(\mathrm{n}=60)$

\section{Sex \\ Male}

Female

Age, years

Mean BMI

Habits

\author{
$40(66.7 \%)$ \\ $20(33.3 \%)$ \\ $56.3 \pm 7.1$ \\ $26.6 \pm 2.8^{\mathrm{a}}$ \\ $30(50 \%)$ \\ $36(60 \%)$
}

$$
\begin{gathered}
40(66.7 \%) \\
20(33.3 \%) \\
56.4 \pm 7.0 \\
25.5 \pm 2.8^{\mathrm{a}} \\
\\
30(50 \%) \\
35(58.3 \%)
\end{gathered}
$$

$40(66.7 \%)$

$20(33.3 \%)$

$56.4 \pm 7.1$

$21.6 \pm 2.1$

Numerical data are expressed as the number (percentage) or mean $\pm \mathrm{SD}$. ${ }^{\mathrm{a}} \mathrm{P}<0.05$ vs. control. $\mathrm{BMI}$, body mass index .

stained with $10 \mu \mathrm{l}$ FITC-Annexin $\mathrm{V}$ and $10 \mu \mathrm{l}$ propidium iodide $(0.5 \mathrm{mg} / \mathrm{ml})$ at $4^{\circ} \mathrm{C}$ in the dark (BD Biosciences), followed by detection of apoptotic cells using flow cytometry. The apoptotic rate was calculated using the percentage of early and late apoptotic cells. Flowjo7.6.1 software (BD Biosciences) was used to analyze flow cytometry data with the BD Accuri C6 flow cytometer (BD Biosciences).

Statistical analysis. Data are presented as the mean \pm standard deviation of three independent replicates obtained in each experiment. SPSS V17.0 (IBM Corp.) was used to perform data analysis. Differences between two groups were analyzed by unpaired t-test. Differences among multiple groups were assessed by one-way ANOVA and post hoc Tukey's test. $\mathrm{P}<0.05$ was considered to indicate a statistically significant difference.

\section{Results}

Differential expression of RPSAP52 in the three groups of participants. The differential expression of RPSAP52 in the three groups of participants was assessed by measuring the expression of RPSAP52 in plasma of patients with DR $(n=60)$, patients with diabetes $(n=60)$ and healthy controls $(n=60)$. It was demonstrated that the plasma expression levels of RPSAP52 were significantly lower in the DR group compared with the other two groups (3.3- and 2.0-fold, respectively; $\mathrm{P}<0.05$; Fig. 1). Moreover, the diabetic group had lower plasma expression levels of RPSAP52 compared with the control group (1.7-fold; $\mathrm{P}<0.05)$.

RPSAP52 may directly interact with miR-365. Prediction of the interaction between RPSAP52 and miR-365 was performed by IntaRNA 2.0. It was identified that RPSAP52 and miR-365 could form base pairing with each other (Fig. 2A). The interaction between them was assessed by dual luciferase reporter assay. Compared with ARPE-19 cells transfected with RPSAP52 vector and miRNA NC, cells co-transfected with RPSAP52 vector and miR-365 mimic had a significantly lower relative luciferase activity (Fig. $2 \mathrm{~B} ; \mathrm{P}<0.05$ ).

RPSAP52 and miR-365 did not affect the expression of each other, but RPSAP52 upregulated Timp3. To further evaluate the interactions between RPSAP52 and miR-365,

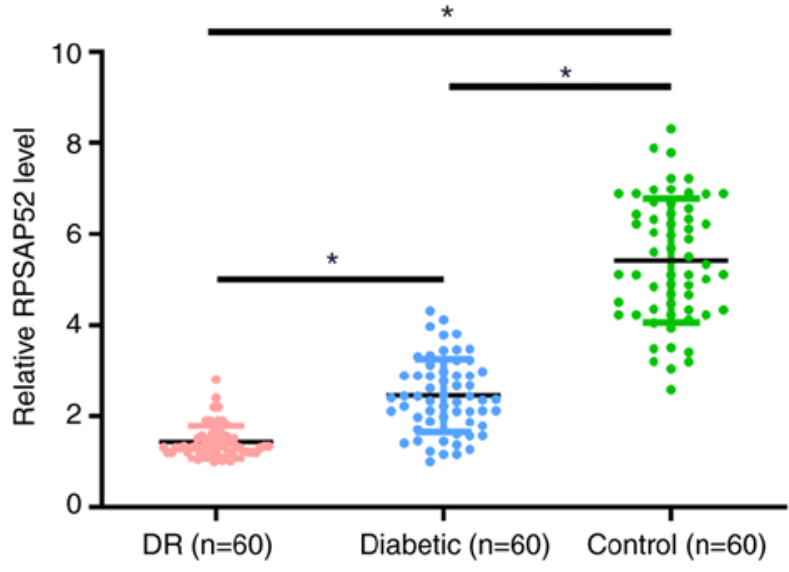

Figure 1. Differential expression of RPSAP52 in the three groups of participants. The differential expression of RPSAP52 in the three groups of participants was evaluated by measuring the expression of RPSAP52 in plasma of patients with DR $(n=60)$, patients with diabetes $(n=60)$ and healthy controls $(n=60)$. PCR reactions were repeated three times and data are presented as the mean $\pm \mathrm{SD}$. ${ }^{*} \mathrm{P}<0.05$. RPSAP52, ribosomal protein $\mathrm{SA}$ pseudogene 52; DR, diabetic retinopathy.

ARPE-19 cells were transfected with RPSAP52 vector and miR-365 mimic. Overexpression of RPSAP52 and miR-365 were demonstrated by RT-qPCR (Fig. 3A; P<0.05). Compared with the NC and $\mathrm{C}$ groups, overexpression of RPSAP52 and miR-365 did not affect the expression of one another (Fig. 3B).

The effects of overexpressing RPSAP52 on the expression of Timp3 at mRNA (Fig. 3C) and protein (Fig. 3D) levels were assessed by RT-qPCR and western blotting, respectively. Compared with $\mathrm{C}$ and NC groups, overexpression of RPSAP52 led to the significant upregulation of Timp3 $(\mathrm{P}<0.05)$.

RPSAP52 regulates the miR-365/Timp3 axis to suppress D-glucose-induced ARPE-19 cell apoptosis. The RT-qPCR results indicated that $\mathrm{D}$-glucose treatment led to downregulation of RPSAP52 (Fig.4A; P<0.05) and Timp3 (Fig.4B; P<0.05), but upregulated miR-365 (Fig. 4C; $\mathrm{P}<0.05$ ).

Cells apoptosis under $30 \mathrm{mM}$ D-glucose treatment after the overexpression of RPSAP52, miR-365 and Timp3 was detected by cell apoptosis assay. The results identified that the apoptotic rate under normal conditions was $2.2 \pm 0.4 \%$, while 
A

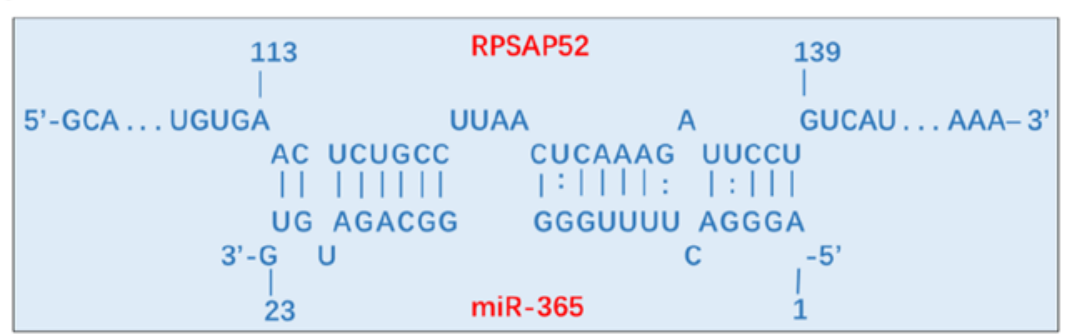

$\mathrm{B}$

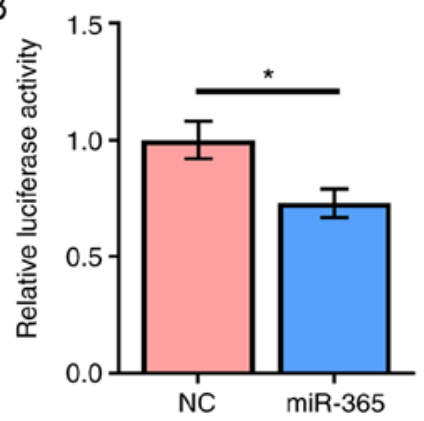

Figure 2. RPSAP52 could directly interact with miR-365. (A) Prediction of the interaction between RPSAP52 and miR-365 was performed using IntaRNA. It was identified that RPSAP52 and miR-365 could form base pairing with each other. (B) Dual luciferase reporter assay was performed by transfecting ARPE-19 cells with RPSAP52 vector and miRNA NC or RPSAP52 vector and miR-365 mimic. Experiments were repeated three times and data are presented as the mean \pm SD. ${ }^{*} \mathrm{P}<0.05$. RPSAP52, ribosomal protein SA pseudogene 52; NC, negative control; miR, microRNA.

A
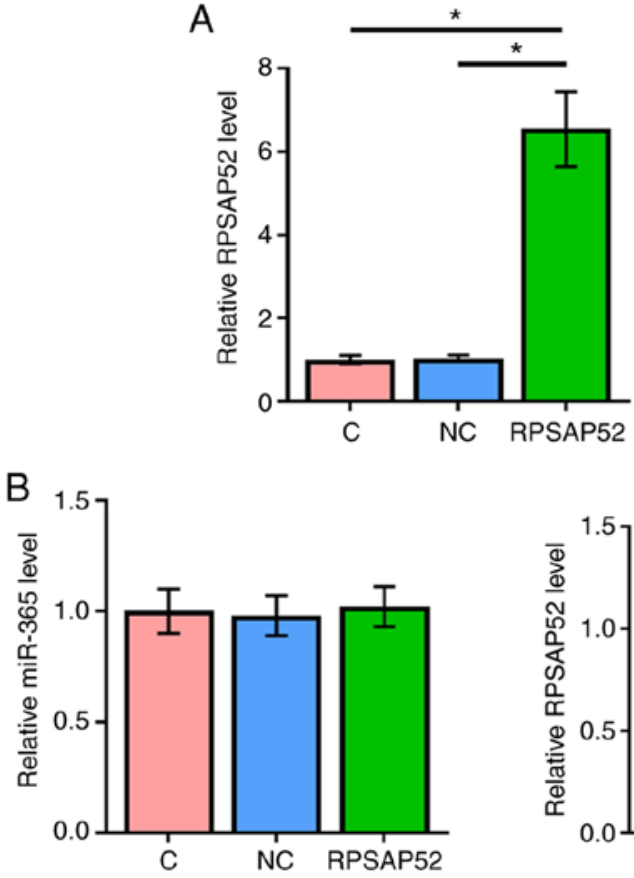

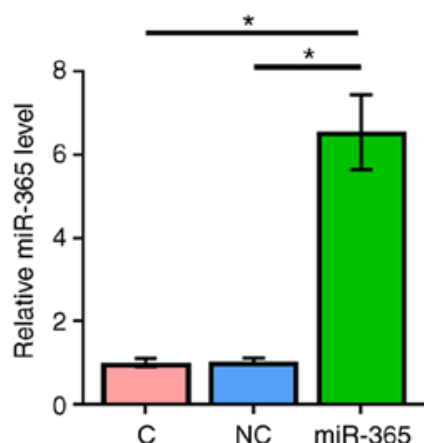

C
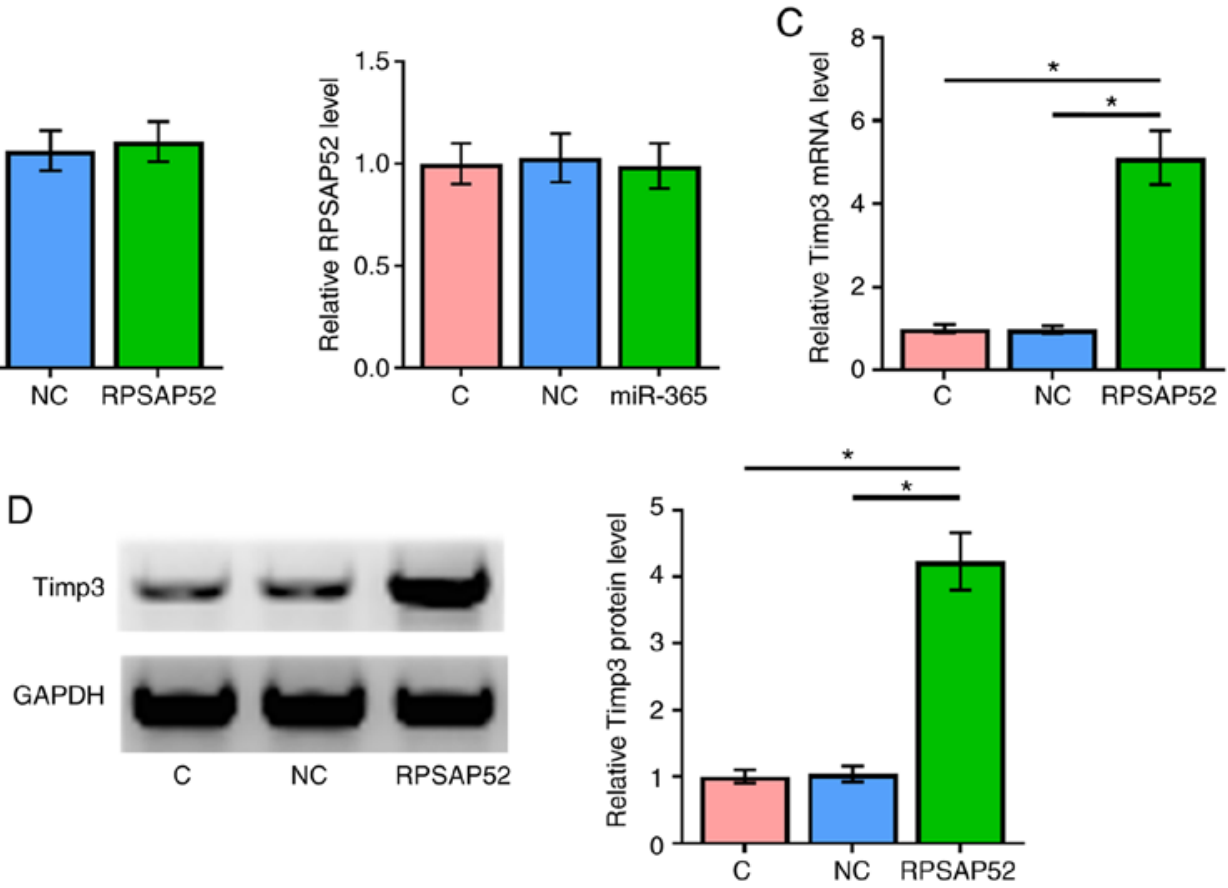

Figure 3. RPSAP52 and miR-365 do not affect the expression of each other, but RPSAP52 upregulates Timp3. ARPE-19 cells were transfected with RPSAP52 expression vector and miR-365 mimic. (A) Overexpression of RPSAP52 and miR-365 was assessed by RT-qPCR at 24 h post-transfection. (B) Effects of overexpression of RPSAP52 and miR-365 on the expression of each other were evaluated by RT-qPCR at $24 \mathrm{~h}$ post-transfection. Effects of the overexpression of RPSAP52 on the expression of Timp3 at (C) mRNA and (D) protein levels were analyzed by RT-qPCR and western blotting, respectively. Experiments were repeated three times and data are presented as the mean $\pm \mathrm{SD}$. ${ }^{*} \mathrm{P}<0.05$. RPSAP52, ribosomal protein SA pseudogene 52 ; NC, negative control; miR, microRNA; Timp3, TIMP metallopeptidase inhibitor 3; C, control; RT-qPCR, reverse transcription-quantitative PCR.

the apoptotic rate of the $\mathrm{C}$ group under $30 \mathrm{mM}$ D-glucose treatment was $6.82 \pm 0.7 \%$, which was significantly different (Fig. 4D; $\mathrm{P}<0.05$ ). Furthermore, overexpression of Timp3 in ARPE-19 cells was evaluated by RT-qPCR (Fig. S1). Compared with the $\mathrm{C}$ group, overexpression of RPSAP52 and Timp3 led to a decreased apoptotic rate of ARPE-19 cells 
A

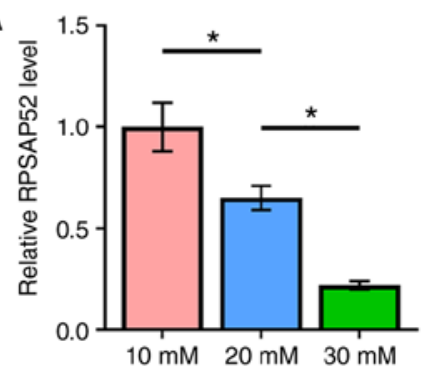

$\mathrm{B}$

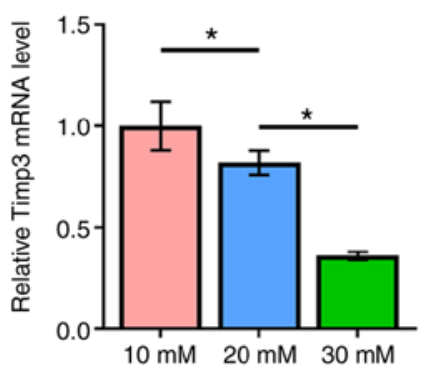

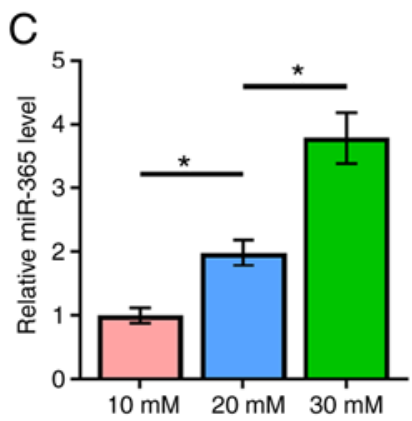
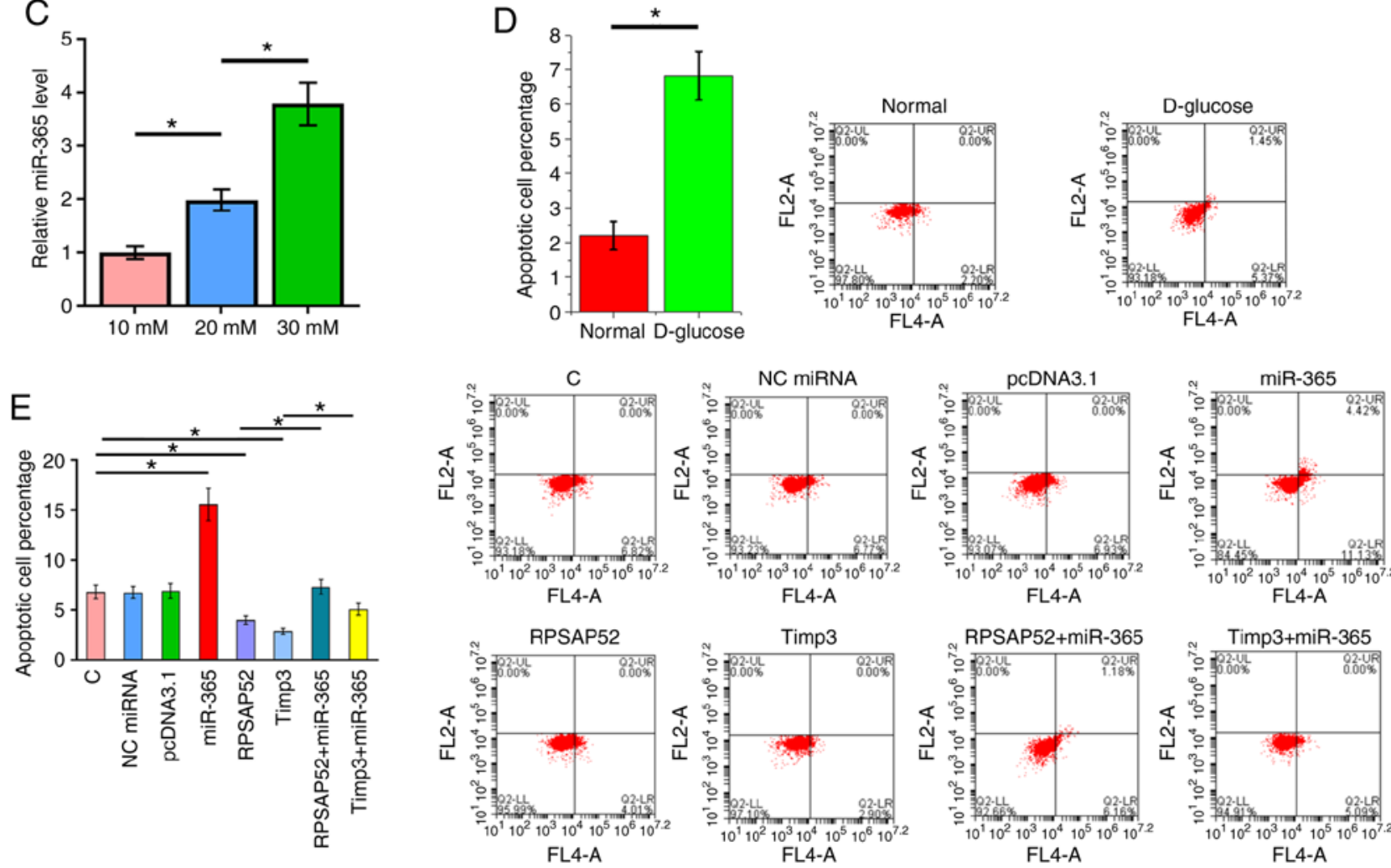

Figure 4. RPSAP52 regulates the miR-365/Timp3 axis to suppress D-glucose-induced ARPE-19 cells apoptosis. Cells were cultivated in DMEM/F12 medium containing 10, 20 and $30 \mathrm{mM}$ D-glucose for $24 \mathrm{~h}$, followed by the measurement of the expression levels of (A) RPSAP52, (B) miR-365 and (C) Timp3 by reverse transcription-quantitative PCR. (D) Effects of D-glucose treatment on the apoptosis of untransfected cells were analyzed by cell apoptosis assay. (E) Cell apoptosis after the overexpression of RPSAP52, miR-365 and Timp3 was analyzed by cell apoptosis assay. Experiments were repeated three times and data are presented as the mean $\pm \mathrm{SD}$. ${ }^{*} \mathrm{P}<0.05$. RPSAP52, ribosomal protein SA pseudogene 52; NC, negative control; miR, microRNA; Timp3, TIMP metallopeptidase inhibitor 3 .

induced by high D-glucose treatment. Moreover, overexpression of miR-365 had an opposite role and reduced the effects of RPSAP52 and Timp3 overexpression (Fig. 4E; P<0.05).

\section{Discussion}

The present study investigated the roles of RPSAP52 in DR. The results suggested that RPSAP52 was downregulated in DR and may regulate the miR-365/Timp3 axis to participate in the regulation of RPE cell apoptosis induced by high D-glucose conditions.

RPSAP52 is a newly identified lncRNA with known functions in pituitary tumors (15). In pituitary tumors, RPSAP52 is overexpressed and can sponge multiple miRNAs, such as miR-15a, miR-15b and miR-16, to regulate the expression of high mobility group A proteins, thus promoting the proliferation of cancer cells (15). It has been reported that RPSAP52 is abundant in the cytoplasm and interacts with the RNA binding protein insulin-like growth factor 2 mRNA-binding protein 2 , and can also play in a role in sarcomas (18). The development and progression of diabetes and its complications can affect the expression of multiple lncRNAs (19); however, to the best of our knowledge, the role of RPSAP52 in diabetes or its complications has not previously reported. The present study identified the downregulation of RPSAP52 in patients with DR and patients with diabetes. Furthermore, high D-glucose treatment led to downregulation of RPSAP52 in RPE. Plasma levels of RPSAP52 were also significantly lower in patients with DR compared with healthy controls. Therefore, the downregulation of RPSAP52 may be induced by the hyperglycemic condition of patients with diabetes. Moreover, with the development of diabetic complications, such as DR, plasma levels of RPSAP52 can be further downregulated. 
RPE cells participate in multiple functions of the eyes, such as light absorption, epithelial transport, spatial buffering of ions and the visual cycle (20). DR induces the apoptosis of RPE cells to reduce the functions of RPE (21). Moreover, the present results indicated a reduced apoptotic rate of RPE cells induced by high D-glucose treatment after overexpression of RPSAP52. Therefore, RPSAP52 may play a protective role in DR.

Previous studies have reported that miR-365 is dysregulated in several human malignancies, such as ovarian cancer (22) and lung cancer (23), and can serve a role in the regulation of the cell cycle and apoptosis (24). Furthermore, high expression of miR-365 is found in the aqueous humor of patients with cataracts (25). It has also been reported that miR-365 can target Timp3 to promote DR and increase oxidative stress (14). Timp3, which is a multifunctional protein, can inhibit matrix metalloproteinases (26). Moreover, it has been shown that a mutation of Timp3 can cause Sorsby funfus dystrophy (27). Timp3 also serves a critical role in glucose homeostasis $(12,13)$, and it has been reported that intravitreal injection of Timp3 can improve retinopathy in a mouse model $(12,13)$. The present results suggested that RPSAP52 could directly interact with miR-365 and overexpression of RPSAP52 caused downregulation of Timp3, which indicated that RPSAP52 may target Timp3 via miR-365. To the best of our knowledge, the present study was the first to identify the involvement of the interaction between Timp3 and miR-365 in RPE cell apoptosis. Moreover, the results suggested that miR-365 may not target RPSAP52. Instead, RPSAP52 could sponge miR-365 to upregulate Timp3, resulting in inhibited RPE cell apoptosis.

It has been previously reported that high D-glucose level induces cell death (28). The present study also confirmed that high D-glucose treatment can induce ARPE-19 cell apoptosis. In addition, the present study did not analyze the correlations between expression levels of RPSA52, Timp3 or miR-365 and the percentage of apoptotic cells. Thus, these will be the focus of future studies.

In conclusion, the present results indicated that RPSAP52 was downregulated in DR and may regulate the miR-365/Timp3 axis to regulate RPE cell apoptosis.

\section{Acknowledgements}

Not applicable.

\section{Funding}

Not applicable.

\section{Availability of data and materials}

The data in this work are available from the corresponding author on reasonable request.

\section{Authors' contributions}

TN and DL designed the experiments. TN and YA performed the experiments. TN and TL analyzed and interpreted the data. TN wrote the manuscript. All authors read and approved the final manuscript.

\section{Ethics approval and consent to participate}

This study was approved by the Ethics Committee of The Fourth People's Hospital of Shenyang. Informed consent was obtained from all participants.

\section{Patient consent for publication}

Not applicable.

\section{Competing interests}

The authors declare that they have no competing interests.

\section{References}

1. Dagenais GR, Gerstein HC, Zhang X, McQueen M, Lear S, Lopez-Jaramillo P, Mohan V, Mony P, Gupta R, Kutty VR, et al: Variations in diabetes prevalence in low-, middle-, and high-income countries: Results from the prospective urban and rural epidemiological study. Diabetes Care 39: 780-787, 2016.

2. Wang L, Gao P, Zhang M, Huang Z, Zhang D, Deng Q, Li Y, Zhao Z, Qin X, Jin D, et al: Prevalence and ethnic pattern of diabetes and prediabetes in China in 2013. JAMA 317: 2515-2523, 2017.

3. Oei L, Rivadeneira F, Zillikens MC and Oei EHG: Diabetes, diabetic complications, and fracture risk. Curr Osteoporos Rep 13: 106-115, 2015.

4. Lee R, Wong TY and Sabanayagam C: Epidemiology of diabetic retinopathy, diabetic macular edema and related vision loss. Eye Vis (Lond) 2: 17, 2015.

5. Nentwich MM and Ulbig MW: Diabetic retinopathy-ocular complications of diabetes mellitus. World J Diabetes 6: 489-499, 2015.

6. Duh EJ, Sun JK and Stitt AW: Diabetic retinopathy: Current understanding, mechanisms, and treatment strategies. JCI Insight 2: e93751, 2017.

7. Hampton BM, Schwartz SG, Brantley MA Jr and Flynn HW Jr: Update on genetics and diabetic retinopathy. Clin Ophthalmol 9: 2175-2193, 2015.

8. Mishra B, Swaroop A and Kandpal RP: Genetic components in diabetic retinopathy. Indian J Ophthalmol 64: 55-61, 2016.

9. Wihandani DM, Suastika K, Bagiada INA and Malik SG: Polymorphisms of aldose reductase (ALR2) regulatory gene are risk factors for diabetic retinopathy in type-2 diabetes mellitus patients in Bali, Indonesia. Open Ophthalmol J 12: 281-288, 2018.

10. Liu E, Kaidonis G, McComish BJ, Gillies MC, Abhary S, Essex RW, Chang JH, Pal B, Daniell M, Lake S, et al: MicroRNA-related genetic variants are associated with diabetic retinopathy in type 1 diabetes mellitus. Invest Ophthalmol Vis Sci 60: 3937-3942, 2019.

11. Babapoor-Farrokhran S, Jee K, Puchner B, Hassan SJ, Xin X, Rodrigues M, Kashiwabuchi F, Ma T, Hu K, Deshpande M, et al: Angiopoietin-like 4 is a potent angiogenic factor and a novel therapeutic target for patients with proliferative diabetic retinopathy. Proc Natl Acad Sci USA 112: E3030-E3039, 2015.

12. Hewing NJ, Weskamp G, Vermaat J, Farage E, Glomski K, Swendeman S, Chan RV, Chiang MF, Khokha R, Anand-Apte B and Blobel CP: Intravitreal injection of TIMP3 or the EGFR inhibitor erlotinib offers protection from oxygen-induced retinopathy in mice. Invest Ophthalmol Vis Sci 54: 864-870, 2013.

13. Federici M, Hribal ML, Menghini R, Kanno H, Marchetti V, Porzio O, Sunnarborg SW, Rizza S, Serino M, Cunsolo V, et al: Timp3 deficiency in insulin receptor-haploinsufficient mice promotes diabetes and vascular inflammation via increased TNF-alpha. J Clin Invest 115: 3494-3505, 2005.

14. Wang J, Zhang J, Chen X, Yang Y, Wang F, Li W, Awuti M, Sun Y, Lian C, Li Z, et al: miR-365 promotes diabetic retinopathy through inhibiting Timp3 and increasing oxidative stress. Exp Eye Res 168: 89-99, 2018.

15. D'Angelo D, Mussnich P, Sepe R, Raia M, Del Vecchio L, Cappabianca P, Pellecchia S, Petrosino S, Saggio S, Solari D, et al: RPSAP52 IncRNA is overexpressed in pituitary tumors and promotes cell proliferation by acting as miRNA sponge for HMGA proteins. J Mol Med (Berl) 97: 1019-1032, 2019. 
16. National Institute on Alcohol Abuse and Alcoholism. Helping patients who drink too much: A clinician's guide: Updated 2005 edition (no. 7). US Department of Health and Human Services, national institutes of health, national institute on alcohol abuse and alcoholism, 2007. https://my.ireta.org/sites/ireta.org/files/ NIAAA_Clinicians_Guide_Helping_Patients.pdf.

17. Livak KJ and Schmittgen TD: Analysis of relative gene expression data using real-time quantitative PCR and the 2(-Delta Delta C(T)) method. Methods 25: 402-408, 2001.

18. Oliveira-Mateos C, Sánchez-Castillo A, Soler M, ObiolsGuardia A, Piñeyro D, Boque-Sastre R, Calleja-Cervantes ME, de Moura MC, Martínez-Cardús A, Rubio T, et al: The transcribed pseudogene RPSAP52 enhances the oncofetal HMGA2-IGF2BP2-RAS axis through LIN28B-dependent and independent let-7 inhibition. Nat Commun 10: 3979, 2019.

19. Leung A and Natarajan R: Long noncoding RNAs in diabetes and diabetic complications. Antioxid Redox Signal 29: 1064-1073, 2018

20. Strauss O: The retinal pigment epithelium in visual function. Physiol Rev 85: 845-881, 2005.

21. Xia T and Rizzolo LJ: Effects of diabetic retinopathy on the barrier functions of the retinal pigment epithelium. Vision Res 139: 72-81, 2017.

22. Wang $\mathrm{Y}, \mathrm{Xu} \mathrm{C}$, Wang $\mathrm{Y}$ and Zhang X: MicroRNA-365 inhibits ovarian cancer progression by targeting Wnt5a. Am J Canc Res 7: 1096-1106, 2017
23. Qi J, Rice SJ, Salzberg AC, Runkle EA, Liao J, Zander DS and Mu D: MiR-365 regulates lung cancer and developmental gene thyroid transcription factor 1. Cell Cycle 11: 177-186, 2012 .

24. Nie J, Liu L, Zheng W, Chen L, Wu X, Xu Y, Du X and Han W: MicroRNA-365, down-regulated in colon cancer, inhibits cell cycle progression and promotes apoptosis of colon cancer cells by probably targeting cyclin D1 and Bcl-2. Carcinogenesis 33 : 220-225, 2012

25. Dunmire JJ, Lagouros E, Bouhenni RA, Jones M and Edward DP: MicroRNA in aqueous humor from patients with cataract. Exp Eye Res 108: 68-71, 2013.

26. Liang J, Chen M, Hughes D, Chumanevich AA, Altilia S, Kaza V, Lim CU, Kiaris H, Mythreye K, Pena MM, et al: CDK8 selectively promotes the growth of colon cancer metastases in the liver by regulating gene expression of TIMP3 and matrix metalloproteinases. Cancer Res 78: 6594-6606, 2018.

27. Weber BH, Vogt G, Pruett RC, Stöhr H and Felbor U: Mutations in the tissue inhibitor of metalloproteinases-3 (TIMP3) in patients with Sorsby's fundus dystrophy. Nat Genet 8: 352-356, 1994.

28. Li Y, Xu F, Xiao H and Han F: Long noncoding RNA BDNF-AS inversely regulated BDNF and modulated high-glucose induced apoptosis in human retinal pigment epithelial cells. J Cell Biochem 119: 817-823, 2018. 